\title{
BMJ
}

\section{Combined impact of lifestyle factors on mortality: prospective cohort study in US women}

\author{
Rob M van Dam, assistant professor of medicine, ${ }^{1,2}$ Tricia Li, research fellow, ${ }^{1}$ Donna Spiegelman, professor \\ of epidemiology and biostatistics, ${ }^{3,4}$ Oscar H Franco, researcher, ${ }^{5}$ Frank B Hu, professor of nutrition and \\ epidemiology $1,2,3$
}

\begin{abstract}
${ }^{1}$ Department of Nutrition, Harvard School of Public Health, 665 Huntington Ave, Boston, MA 02115, USA

${ }^{2}$ Channing Laboratory, Department of Medicine, Brigham and Women's Hospital, and Harvard Medical School, Boston MA 02115

${ }^{3}$ Department of Epidemiology, Harvard School of Public Health

${ }^{4}$ Department of Biostatistics, Harvard School of Public Health

${ }^{5}$ Unilever Corporate Research, Sharnbrook, Bedfordshire MK44 1LQ

Correspondence to: $\mathrm{R}$ van Dam rvandam@hsph.harvard.edu
\end{abstract}

Cite this as: BMJ 2008;337:a1440 doi:10.1136/bmj.a1440

\section{ABSTRACT}

Objective To evaluate the impact of combinations of lifestyle factors on mortality in middle aged women.

Design Prospective cohort study.

Setting Nurses' health study, United States.

Participants 77782 women aged 34 to 59 years and free from cardiovascular disease and cancer in 1980.

Main outcome measure Relative risk of mortality during 24 years of follow-up in relation to five lifestyle factors (cigarette smoking, being overweight, taking little moderate to vigorous physical activity, no light to moderate alcohol intake, and low diet quality score). Results 8882 deaths were documented, including 1790 from cardiovascular disease and 4527 from cancer. Each lifestyle factor independently and significantly predicted mortality. Relative risks for five compared with zero lifestyle risk factors were 3.26 (95\% confidence interval 2.45 to 4.34 ) for cancer mortality, 8.17 (4.96 to 13.47) for cardiovascular mortality, and 4.31 (3.51 to 5.31) for all cause mortality. A total of $28 \%$ (25\% to $31 \%$ ) of deaths during follow-up could be attributed to smoking and $55 \%$ ( $47 \%$ to $62 \%$ ) to the combination of smoking, being overweight, lack of physical activity, and a low diet quality. Additionally considering alcohol intake did not substantially change this estimate.

Conclusions These results indicate that adherence to lifestyle guidelines is associated with markedly lower mortality in middle aged women. Both efforts to eradicate cigarette smoking and those to stimulate regular physical activity and a healthy diet should be intensified.

\section{INTRODUCTION}

Diet, physical activity, adiposity, alcohol consumption, and cigarette smoking have been associated with risk of chronic diseases including type 2 diabetes, ${ }^{12}$ cardiovascular diseases, ${ }^{3-5}$ and various cancers. ${ }^{67}$ However, to identify priorities for clinical and public health efforts, understanding the magnitude of effects of risk factors, individually and in combination, on overall health is fundamental. One way to assess the impact of lifestyle factors on overall health is to evaluate the effects on mortality, which allows comparison of the magnitude of effects of individual factors as well as estimation of combined effects.
The proportion of deaths that is attributable to lifestyle factors has been estimated by Mokdad and colleagues and in the global burden of disease study, using data on relative risks and the prevalence of risk factors from multiple sources. ${ }^{89}$ As a result of this broad approach, the imprecision and potential biases affecting the results were less transparent and the analysis of lifestyle factors was less detailed than can be achieved in a well characterised prospective cohort study. In a cohort study in 11 European countries, an estimated $60 \%$ of deaths from all causes during 10 years of followup could be attributed to lack of adherence to nonsmoking, a healthy diet, regular physical activity, and moderate alcohol intake. ${ }^{10}$ However, this study included only 2339 participants, who were elderly and mostly male, and whether the findings apply to younger populations and women thus remains unclear. We therefore examined combinations of lifestyle factors in relation to cancer, cardiovascular, and all cause mortality during 24 years of follow-up among middle aged women who participated in the nurses' health study. We also estimated population attributable risks, the proportion of deaths during follow-up that could potentially have been avoided by adherence to lifestyle guidelines.

\section{METHODS}

\section{Study population}

The nurses' health study is a prospective cohort study that was established in 1976 when 121700 female registered US nurses, aged 30 to 55 years, completed a mailed questionnaire on known and suspected risk factors for chronic diseases. Since then, participants have been sent biennial follow-up questionnaires to update information on lifestyle and health conditions. For the current analysis, we began follow-up in 1980, because this was the first year when diet was assessed. In 1980, 98462 women, aged 34 to 59 years, completed the questionnaire. We excluded women with previously diagnosed cancer (except non-melanoma skin cancer) or cardiovascular disease $(n=8527)$. We also excluded alcohol abstainers who reported on the 1980 questionnaire a great decrease in alcohol consumption during the previous decade $(n=2797)$, because this 


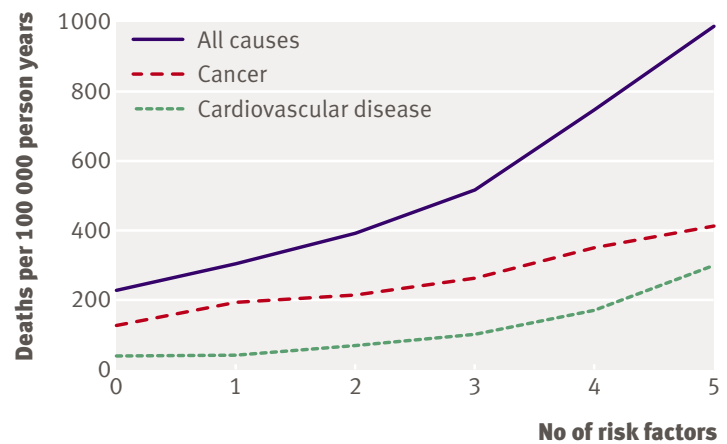

Age standardised all cause, cancer, and cardiovascular mortality during 24 years of follow-up by number of lifestyle risk factors. Lifestyle risk factors included cigarette smoking (ever), lack of physical activity ( $\$ 30 \mathrm{~min} /$ day moderate to vigorous intensity activity), low diet quality (lowest three fifths of healthy diet score), alcohol intake of 0 or $\geq 15 \mathrm{~g} /$ day, and overweight (body mass index $\geq 25$ )

could be subsequent to alcoholism or disease. Similarly, we excluded women with a body mass index below 18.5 ( $n=1848)$, because this may be due to weight loss secondary to preclinical diseases. ${ }^{11}$ Finally, we excluded participants who left 10 or more items blank on the 1980 diet questionnaire, those with implausibly high or low reported energy intakes (below 2.09 or above $14.63 \mathrm{MJ} /$ day), those with ages outside the eligible range, and those with missing information for smoking or body mass index $(n=7562)$. After exclusions, a total of 77782 women remained for the current analysis. Completion of the questionnaire was considered to imply informed consent.

\section{Assessment of risk factors}

Diet was assessed with a 61 item food frequency questionnaire in $1980 .{ }^{12}$ An expanded questionnaire including approximately 120 food items was used to update information about diet every two to four years. Participants were asked how often, on average, during the previous year they had consumed a specified common unit or portion size of a specific type of food The participants could choose from nine response categories ranging from "never or less than once a month" to "six or more times a day." Nutrient intakes were calculated by summing the nutrient content of a unit of each food multiplied by a weight proportional to the frequency of its use. Validation studies in this cohort using biochemical markers and diet records as references indicated that the food frequency questionnaire estimated dietary intakes with reasonably good accuracy. ${ }^{12-14}$

Information on disease history and cigarette smoking was assessed on each biennial questionnaire. Frequency of physical activity during the previous year was assessed in 1980, and this information was updated every two to four years. ${ }^{15}$ Height (in inches) was assessed in the 1976 questionnaire, weight (in pounds) was assessed on the 1980 questionnaire, and the body mass index was calculated as weight in kilograms divided by the square of height in metres. In our validation study, the correlation between self reported and technician measured weight was $0.97 .{ }^{16}$ Father's occupation when the participant was 16 years of age was assessed on the 1976 questionnaire. In 1992, we also asked about the degrees the participant had received (registered nurse, bachelors, masters, doctorate) and, for women who were married or widowed, the highest level of education that their husband completed (less than high school, some high school, high school graduate, college graduate, graduate school).

\section{Classification of low risk categories}

or adiposity, we defined low risk as a body mass index between 18.5 and 25.0. ${ }^{17}$ For physical activity, we defined low risk as an average of at least 30 minutes a day of activity of at least moderate intensity (requiring $\geq 3$ metabolic equivalents an hour, including brisk walking), consistent with existing guidelines. ${ }^{18}$ For cigarette smoking, we defined low risk as never smoking. For alcohol consumption, we defined low risk as light to moderate consumption $(\geq 1$ and $<15 \mathrm{~g} /$ day - that is, up to approximately one drink a day).

To quantify the healthiness of the diet, we used the previously designed alternative healthy eating score. ${ }^{19}$ For this analysis, we decided a priori to use only seven of the nine original items: we did not include multivitamin intake, because this has become less relevant as a folate source as a result of widespread fortification of foods, and we did not include alcohol intake, because we wanted to present results on alcohol intake separately. For each of the remaining seven items, we assigned a score between 0 (least healthy) and 10 (recommended intake). We then added the scores for the individual items, resulting in a minimum healthy diet score of 0 and a maximum healthy diet score of 70 . The seven included items were vegetables (recommended: at least five servings a day), fruit (at least four servings a day), nuts and soya (at least one serving a day), ratio of fish and poultry to red meat (ratio at least four or red meat less than twice a month), cereal fibre $(\geq 15 \mathrm{~g} /$ day $)$, trans-fat $(\leq 0.5 \%$ of total energy), and the polyunsaturated to saturated fatty acid ratio (ratio at least one). ${ }^{19}$ We considered participants with a healthy diet score in the upper two fifths (highest 40\%) to be in the low risk category for diet.

\section{Ascertainment of mortality}

Deaths were reported by next of kin, the postal authorities, or both or were ascertained through searching for non-responders in the National Death Index. Follow-up for deaths in the National Death Index has been estimated to be $98 \%$ complete for this cohort. $^{20}$ Information on the cause of death was obtained from the next of kin (for external deaths such as those due to traffic accidents), death certificates, or medical records. We requested permission from the next of kin to review medical records for suspected deaths due to cancer or cardiovascular diseases if we did not yet have these records for follow-up of disease incidence. The cause of death was determined after 
review by physicians and primarily based on medical records if both medical records and death certificates were available. We used ICD-8 (international classification of diseases, 8th revision) codes to distinguish deaths due to cancer (140-207) and cardiovascular diseases (390-459 and 795).

\section{Statistical analysis}

Women contributed follow-up time from the date of return of the baseline questionnaire to the date of death or 1 June 2004, whichever came first. We used pooled logistic regression analysis stratified by two year calendar time periods to estimate multivariate relative risks and corresponding 95\% confidence intervals. We chose this method because it obtains all information needed for the calculation of partially adjusted population attributable risk estimates, including estimation of the relative risks for age. ${ }^{21}$ Pooled logistic regression analysis is asymptotically equivalent to Cox proportional hazards regression if time intervals are relatively short and the probability of the outcome in the intervals is small, ${ }^{22}$ conditions that were satisfied for this analysis.

We calculated population attributable risks, which are estimates of the percentage of deaths during followup that would not have occurred if all women had been in the low risk category for lifestyle factors, assuming that the observed associations represent causal effects. For these analyses, we compared women in the low risk category for each of the component risk factors with all other women. ${ }^{23}$ We calculated population attributable risks by using previously described formulas that were elaborated for this specific study design and are appropriate for use with multivariate adjusted relative risks (SAS macro: www.hsph.harvard.edu/faculty/ spiegelman/software.html). ${ }^{212425}$ Because of the large computational computer capacity needed for this calculation, we reduced the number of categories for the covariable calendar time by combining 12 two year time periods into four periods. We estimated prevalence of exposures for 1990, because this year is

Table 1 | Multivariate relative risk of death from any cause, cardiovascular disease, and cancer during 24 years of follow-up according to body mass index, cigarette smoking, alcohol consumption, physical activity, and diet*

\begin{tabular}{|c|c|c|c|c|c|c|c|}
\hline & \multirow[b]{2}{*}{ Person years } & \multicolumn{2}{|c|}{ Deaths from any cause } & \multicolumn{2}{|c|}{ Cardiovascular deaths } & \multicolumn{2}{|c|}{ Cancer deaths } \\
\hline & & Cases & Relative risk $(95 \% \mathrm{Cl})$ & Cases & Relative risk $(95 \% \mathrm{Cl})$ & Cases & Relative risk $(95 \% \mathrm{Cl})$ \\
\hline \multicolumn{8}{|c|}{ Body mass index $\left(\mathrm{kg} / \mathrm{m}^{2}\right)$} \\
\hline $18.5-24.9$ & 1174514 & 5095 & 1.00 (1.00 to 1.00$)$ & 855 & 1.00 (1.00 to 1.00$)$ & 2747 & 1.00 (1.00 to 1.00$)$ \\
\hline $25-29.9$ & 404856 & 2359 & $1.18(1.12$ to 1.24$)$ & 511 & 1.46 (1.31 to 1.63$)$ & 1195 & 1.14 (1.06 to 1.22$)$ \\
\hline$\geq 30.0$ & 180039 & 1428 & 1.67 (1.57 to 1.78$)$ & 424 & 2.81 (2.49 to 3.17$)$ & 585 & 1.32 (1.21 to 1.45$)$ \\
\hline \multicolumn{8}{|l|}{ Cigarette smoking } \\
\hline Never & 787104 & 2998 & 1.00 (1.00 to 1.00$)$ & 595 & 1.00 (1.00 to 1.00$)$ & 1519 & 1.00 (1.00 to 1.00$)$ \\
\hline Past & 667250 & 4076 & 1.52 (1.44 to 1.59$)$ & 743 & 1.49 (1.33 to 1.66$)$ & 2079 & 1.47 (1.37 to 1.57$)$ \\
\hline $\begin{array}{l}\text { Current 1-14/ } \\
\text { day }\end{array}$ & 104428 & 609 & 1.94 (1.77 to 2.12 ) & 145 & 2.61 (2.17 to 3.14) & 318 & 1.82 (1.61 to 2.06$)$ \\
\hline Current $\geq 15 /$ day & 200626 & 1199 & 2.32 (2.16 to 2.49$)$ & 307 & 3.34 (2.88 to 3.87$)$ & 611 & 2.10 (1.90 to 2.32$)$ \\
\hline \multicolumn{8}{|c|}{ Alcohol consumption† (g/day) } \\
\hline 0 & 386395 & 2044 & $1.00(1.00$ to 1.00$)$ & 502 & $1.00(1.00$ to 1.00$)$ & 887 & 1.00 (1.00 to 1.00$)$ \\
\hline $1-4$ & 745039 & 3589 & 0.81 (0.76 to 0.85$)$ & 712 & 0.69 (0.61 to 0.77$)$ & 1878 & 0.97 (0.90 to 1.06$)$ \\
\hline $5-14$ & 405344 & 1861 & $0.80(0.75$ to 0.86$)$ & 324 & $0.63(0.54$ to 0.73$)$ & 1023 & 0.99 (0.90 to 1.09$)$ \\
\hline $15-29$ & 155024 & 900 & 0.90 (0.83 to 0.98$)$ & 168 & $0.75(0.62$ to 0.90$)$ & 492 & $1.11(0.99$ to 1.24$)$ \\
\hline$\geq 30$ & 67369 & 485 & 1.11 (1.00 to 1.23$)$ & 82 & 0.75 (0.59 to 0.96$)$ & 246 & 1.26 (1.09 to 1.46$)$ \\
\hline \multicolumn{8}{|c|}{ Physical activity $\ddagger$ (hours/week) } \\
\hline $0-0.4$ & 116915 & 1143 & 1.00 (1.00 to 1.00$)$ & 231 & 1.00 (1.00 to 1.00$)$ & 513 & 1.00 (1.00 to 1.00$)$ \\
\hline $0.5-1.9$ & 596872 & 3366 & 0.84 (0.78 to 0.90$)$ & 715 & 0.94 (0.81 to 1.09$)$ & 1644 & 0.88 (0.79 to 0.97$)$ \\
\hline $2.0-3.4$ & 370631 & 1690 & 0.77 (0.71 to 0.83$)$ & 345 & $0.87(0.73$ to 1.03$)$ & 896 & $0.83(0.75$ to 0.93$)$ \\
\hline $3.5-5.4$ & 201459 & 768 & 0.72 (0.65 to 0.79$)$ & 126 & $0.70(0.56$ to 0.87$)$ & 446 & $0.82(0.72$ to 0.94$)$ \\
\hline$\geq 5.5$ & 248639 & 636 & $0.63(0.57$ to 0.69$)$ & 96 & 0.57 (0.45 to 0.73$)$ & 379 & $0.73(0.64$ to 0.84$)$ \\
\hline \multicolumn{8}{|c|}{ Healthy diet score§ } \\
\hline Fifth 1 & 337747 & 2122 & 1.00 (1.00 to 1.00$)$ & 443 & 1.00 (1.00 to 1.00$)$ & 1038 & 1.00 (1.00 to 1.00$)$ \\
\hline Fifth 2 & 348559 & 1848 & 0.85 (0.79 to 0.90$)$ & 427 & $0.96(0.84$ to 1.10$)$ & 891 & $0.83(0.76$ to 0.91$)$ \\
\hline Fifth 3 & 355705 & 1766 & $0.80(0.75$ to 0.85$)$ & 344 & 0.78 (0.67 to 0.90$)$ & 895 & 0.81 (0.74 to 0.89$)$ \\
\hline Fifth 4 & 359442 & 1701 & $0.76(0.71$ to 0.81$)$ & 326 & $0.75(0.65$ to 0.87$)$ & 894 & $0.80(0.73$ to 0.87$)$ \\
\hline Fifth 5 & 357955 & 1445 & 0.65 (0.61 to 0.70$)$ & 250 & $0.59(0.51$ to 0.70$)$ & 809 & 0.72 (0.65 to 0.79$)$ \\
\hline
\end{tabular}

*Relative risks adjusted for age ( 5 year categories), time period (12 periods), and other risk factors included in table.

†Three deaths and 239 person years not included because of missing values.

fOf moderate to vigorous intensity; 1279 deaths and 224893 person years not included because of missing values.

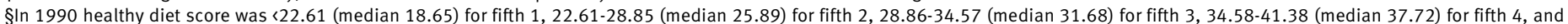
$>41.39$ (median 46.34) for fifth 5. 
midway during follow-up and approximates average exposure during follow-up.

To estimate relative risks for cigarette smoking and diet, we updated information during follow-up by using the most recently available information. For physical activity and alcohol intake, we used the cumulative average from all available questionnaires up to the start of each two year follow-up. ${ }^{26}$ To minimise bias owing to the effects of poor health before death leading to weight loss, ${ }^{11}$ we used the baseline (1980) body mass index in our analysis. In a sensitivity analysis, we examined potential confounding by measures of socioeconomic status by adding father's occupation, education degree received by the participant, and education level of the husband to the multivariate model. Because education level was only assessed in 1992, we did this analysis for follow-up from 1992 until 2004.

We considered two tailed $\mathrm{P}$ values lower than 0.05 to be statistically significant. We used SAS software, version 9.1 for all analyses.

\section{RESULTS}

During 1759408 person years of follow-up we documented 8882 deaths, including 1790 from cardiovascular disease and 4527 from cancer. Table 1 shows the multivariate adjusted relative risks for lifestyle factors and death during follow-up. Cigarette smoking, higher body mass index, less physical activity, and a lower healthy diet score were all associated with increased cardiovascular, cancer, and all cause mortality. Alcohol consumption was associated with a lower risk of cardiovascular mortality than alcohol abstinence. However, heavy alcohol consumption was associated with an increased risk of cancer mortality. As a result, light to moderate alcohol consumption was associated with the lowest all cause mortality.

Table 2 shows the multivariate adjusted relative risks and population attributable risks of mortality for the high risk compared with the low risk category of lifestyle factors. The estimated population attributable risks were $28 \%$ for cigarette smoking, $14 \%$ for being overweight, $17 \%$ for lack of physical activity, $13 \%$ for low diet quality, and $7 \%$ for not having light to moderate alcohol consumption. Population attributable risks were higher for cardiovascular mortality than for cancer mortality. Among never smokers, the relative risk of mortality for being overweight was higher than that for the whole study population $(1.55,95 \%$ confidence interval 1.44 to $1.66)$, resulting in a higher population attributable risk $(22 \%, 18 \%$ to $27 \%)$.

We also evaluated combinations of lifestyle risk factors in relation to mortality. As shown in the figure, cardiovascular, cancer, and all cause mortality increased with an increasing number of risk factors. The relative risk for combining cigarette smoking, being overweight, lack of physical activity, and a low healthy diet score compared with none of the risk factors was 6.91 (4.50 to 10.63) for cardiovascular mortality, 2.65 (2.14 to 3.28) for cancer mortality, and 3.41 (2.90 to 4.00 ) for all cause mortality (table 3 ). The population attributable risk for having any of these four risk factors was $72 \%$ for cardiovascular mortality, $44 \%$ for cancer mortality, and 55\% for all cause mortality. When we also considered alcohol consumption, the population attributable risks for having any of the five lifestyle risk factors were modestly greater than for the four risk factors (table 3).

Results among never smokers were consistent with those for the whole study population (table 4). We also examined whether results differed for younger $(<60$ years) and older $(\geq 60$ years $)$ participants by recalculating the relative risks for these subgroups and using the prevalence of risk factor specific for these subgroups. The population attributable risk for all cause mortality for the five risk factors combined (smoking, diet, physical activity, overweight, alcohol consumption) was $51 \%(30 \%$ to $67 \%)$ for younger women and $63 \%$ $(52 \%$ to $72 \%)$ for older women. Finally, we examined potential confounding by measures of socioeconomic status (father's occupation, education level of participant and husband). Adjustment for these variables did not materially alter the association between any of the lifestyle factors and mortality during follow-up (data not shown).

\section{DISCUSSION}

In this study of 77782 middle aged US women, never smoking, engaging in regular physical activity, eating a

\begin{tabular}{|c|c|c|c|c|c|c|c|}
\hline \multirow[b]{2}{*}{ Variable } & \multirow{2}{*}{$\begin{array}{l}\text { Women in high risk } \\
\text { category (\%) } \dagger\end{array}$} & \multicolumn{2}{|c|}{ Death from any cause } & \multicolumn{2}{|c|}{ Cardiovascular death } & \multicolumn{2}{|c|}{ Cancer death } \\
\hline & & Relative risk & PAR (\%) & Relative risk & PAR (\%) & Relative risk & PAR (\%) \\
\hline Ever $v$ never smoking & 56 & $1.66(1.59$ to 1.74$)$ & 27.9 (24.6 to 31.2$)$ & 1.83 (1.65 to 2.02$)$ & 32.7 (25.7 to 39.4$)$ & 1.59 (1.49 to 1.70$)$ & 26.8 (21.3 to 31.3$)$ \\
\hline Body mass index $\geq 25 \vee 18.5-24.9$ & 48 & $1.32(1.27$ to 1.38$)$ & $14.2(11.6$ to 16.9$)$ & 1.85 (1.68 to 2.04$)$ & $30.6(25.5$ to 35.4$)$ & 1.19 (1.12 to 1.27$)$ & 8.3 (4.4 to 12.2$)$ \\
\hline $\begin{array}{l}\text { Physical activity }<30 \mathrm{~min} / \text { day } v \\
\geq 30 \mathrm{~min} / \text { day }\end{array}$ & 75 & 1.25 (1.17 to 1.32$)$ & 16.5 (11.7 to 21.1$)$ & 1.47 (1.27 to 1.69$)$ & 27.7 (17.2 to 37.5$)$ & 1.13 (1.05 to 1.22$)$ & 9.3 (2.7 to 15.9$)$ \\
\hline $\begin{array}{l}\text { Healthy diet score in lower three } \\
\text { fifths } v \text { upper two fifths }\end{array}$ & 59 & 1.25 (1.19 to 1.30$)$ & $12.9(9.6$ to 16.2$)$ & 1.35 (1.22 to 1.50$)$ & 17.7 (10.3 to 25$)$ & 1.16 (1.09 to 1.24$)$ & 8.8 (4.1 to 13.4$)$ \\
\hline $\begin{array}{l}\text { Heavier drinking or abstaining } \neq v \\
\text { light to moderate alcohol intake }\end{array}$ & 34 & $1.18(1.13$ to 1.24$)$ & 7.4 (4.6 to 10.2$)$ & 1.31 (1.19 to 1.44$)$ & $11.3(4.9$ to 17.5$)$ & $1.06(1.00$ to 1.12$)$ & 3.1 (0.8 to 5.3$)$ \\
\hline
\end{tabular}

*Relative risks and population attributable risks adjusted for age ( 5 year categories), time period (four periods), and other risk factors included in table.

†Based on prevalence in 1990.

$\ddagger 0$ or $\geq 15 \mathrm{~g} /$ day alcohol. 


\begin{tabular}{|c|c|c|c|}
\hline & Death from any cause & Cardiovascular death & Cancer death \\
\hline \multicolumn{4}{|c|}{ Four risk factors: smoking, overweight, low diet quality, low physical activity† } \\
\hline \multicolumn{4}{|l|}{ Relative risk $(95 \% \mathrm{Cl})$ : } \\
\hline No risk factors (3.4\%) $\ddagger$ & 1.00 & 1.00 & 1.00 \\
\hline One risk factor (16\%) & 1.30 (1.10 to 1.53$)$ & $1.43(0.91$ to 2.24$)$ & $1.32(1.06$ to 1.63$)$ \\
\hline Two risk factors (33\%) & 1.75 (1.49 to 2.05$)$ & $2.42(1.58$ to 3.71$)$ & 1.61 (1.231 to 1.98$)$ \\
\hline Three risk factors (34\%) & $2.52(2.15$ to 2.95$)$ & $3.98(2.60$ to 6.08$)$ & $2.12(1.73$ to 2.60$)$ \\
\hline Four risk factors (13\%) & $3.41(2.90$ to 4.00$)$ & $6.91(4.50$ to 10.63$)$ & 2.65 (2.14 to 3.28$)$ \\
\hline $\begin{array}{l}\text { Population attributable risk (\%) for } \\
\text { having any of the four risk factors ( } 95 \% \\
\text { Cl) }\end{array}$ & $54.8(46.7$ to 61.9$)$ & 72.0 (58.6 to 81.6$)$ & $44.3(31.2$ to 55.8$)$ \\
\hline \multicolumn{4}{|c|}{ Five risk factors: above four and alcohol abstinence or heavy drinking§ } \\
\hline \multicolumn{4}{|l|}{ Relative risk $(95 \% \mathrm{Cl})$ : } \\
\hline No risk factors $(2.4 \%) \ddagger$ & 1.00 & 1.00 & 1.00 \\
\hline One risk factor (12\%) & 1.34 (1.09 to 1.64$)$ & $1.13(0.67$ to 1.89$)$ & 1.55 (1.18 to 2.02$)$ \\
\hline Two risk factors ( $27 \%)$ & 1.70 (1.40 to 2.07$)$ & 1.88 (1.15 to 3.05$)$ & 1.71 (1.32 to 2.22$)$ \\
\hline Three risk factors (34\%) & 2.25 (1.85 to 2.72$)$ & $2.80(1.73$ to 4.54$)$ & 2.07 (1.60 to 2.68$)$ \\
\hline Four risk factors (21\%) & 3.27 (2.70 to 3.97$)$ & $4.77(2.94$ to 7.72$)$ & $2.79(2.15$ to 3.62$)$ \\
\hline Five risk factors ( $4.2 \%)$ & $4.31(3.51$ to 5.31$)$ & 8.17 (4.96 to 13.47$)$ & $3.26(2.45$ to 4.34$)$ \\
\hline $\begin{array}{l}\text { Population attributable risk (\%) for } \\
\text { having any of the five risk factors ( } 95 \% \\
\text { Cl) }\end{array}$ & $58.1(49.3$ to 65.7$)$ & $75.2(60.9$ to 84.7$)$ & $46.0(31.7$ to 58.3$)$ \\
\hline \multicolumn{4}{|c|}{$\begin{array}{l}\text { *Relative risks and population attributable risks adjusted for age ( } 5 \text { year age categories) and time period (four periods); additionally adjusted fo } \\
\text { alcohol consumption }(0,1-4,5-14,15-29, \geq 30 \mathrm{~g} / \mathrm{d}) \text { for "four risk factor" model. } \\
\text { †Overweight: body mass index } \geq 25 \text {; low diet quality: healthy diet score in lower three fifths; low physical activity: }<30 \mathrm{~min} / \text { day. } \\
\text { †Prevalence in } 1990 \text {. } \\
\S 0 \text { or } \geq 15 \mathrm{~g} / \text { day alcohol. }\end{array}$} \\
\hline
\end{tabular}

healthy diet, and avoiding becoming overweight were each associated with a markedly lower mortality during 24 years of follow-up. We estimated that $55 \%$ of all cause mortality, $44 \%$ of cancer mortality, and $72 \%$ of cardiovascular mortality during follow-up could have been avoided by adherence to these four lifestyle guidelines. Light to moderate alcohol consumption (up to one drink a day) was also associated with a lower risk of all cause mortality during follow-up.

\section{Results in relation to other studies}

Smoking, overweight, physical activity, and quality of diet have consistently been associated with risk of chronic diseases and mortality in prospective cohort studies. ${ }^{671011181927}$ Not all of these risk factors have been studied in randomised controlled trials with disease incidence or mortality end points, and this may never be done for feasibility or ethical reasons. However, findings from randomised controlled trials support the protective effect of a prudent Mediterranean-style diet and substitution of polyunsaturated for saturated fat for coronary heart disease ${ }^{34}$; of the combination of physical activity, a healthy diet, and moderate weight loss for type 2 diabetes $^{2}$; and of smoking cessation for premature mortality. ${ }^{28}$ In addition, randomised controlled trials have shown beneficial effects of moderate alcohol consumption, reduced trans-fat intake, high fruit and vegetable intake, and whole grain intake on biological markers of cardiovascular risk. $^{29-32}$
Few previous studies have examined combinations of lifestyle factors in relation to mortality. In the EPICNorfolk study, lifestyle factors were studied in relation to mortality in men and women aged 45 to 79 years during an average of 11 years of follow-up. Participants who smoked, were physically inactive, were nonmoderate alcohol consumers, and had low fruit and vegetable intakes (measured by plasma vitamin $\mathrm{C}$ concentrations) had a relative risk of all cause mortality during follow-up of 4.04 (2.95 to 5.54) compared with participants who met none of these criteria. ${ }^{27}$ In another British prospective study, the estimated probability of surviving 15 years free of cardiovascular events and diabetes for a man aged 50 years ranged from $89 \%$ in a moderately physically active man with a body mass index between 20 and 24 who had never smoked to $42 \%$ in an inactive smoker with a body mass index of 30 or higher. ${ }^{33}$ In a cohort of elderly Europeans aged 70 to 90 years, the combination of non-smoking, a Mediterranean-style diet, regular physical activity, and moderate alcohol consumption was associated with a relative risk of 10 year all cause mortality of 0.35 (0.28 to 0.44$)$ compared with adherence to only one or fewer of these lifestyle factors..$^{10}$ The estimated population attributable risk for the combination of lifestyle factors was $60 \%$ for all cause mortality, $61 \%$ for cardiovascular mortality, and $60 \%$ for cancer mortality. For women in high income countries in the global burden of disease study, the estimated population attributable risk for mortality was $14 \%$ for smoking, $8 \%$ for overweight, $5 \%$ for physical 
inactivity, 4\% for low fruit and vegetable intake, and $-3 \%$ for alcohol use. ${ }^{9}$ Mokdad and colleagues estimated that the population attributable risks for US mortality in 2000 was $18 \%$ for tobacco, $15 \%$ for poor diet and physical inactivity, and 3.5\% for excess alcohol consumption. ${ }^{8}$ Thus, our results are consistent with those from previous cohort studies that included European and male participants and suggest that the population attributable risk estimates from studies using an indirect approach may be conservative for the demographic group that we studied.

Heavy alcohol consumption was associated with higher cancer mortality in our study and has been associated with an increased risk of various cancers, liver cirrhosis, hypertension, psychiatric disorders, injuries, and violence in other studies. ${ }^{345}$ Consistent with previous studies, ${ }^{1036}$ we found that light to moderate alcohol consumption was associated with lower cardiovascular mortality. However, even moderate alcohol consumption has been associated with a higher risk of breast cancer and traffic accidents. ${ }^{3537}$ In addition, people with moderate alcohol consumption may be more likely to transition to heavy consumption, and a greater average alcohol consumption may facilitate heavy consumption in communities. ${ }^{38}$ For individual people, the balance of risks and benefits of moderate alcohol consumption may depend on other characteristics; possible benefits may exist for older women with cardiovascular risk factors,${ }^{39}$ and a greater likelihood of adverse effects may exist for women with a personal or family history of alcoholism, alcohol related cancers, or risk factors for these conditions. ${ }^{3537}$ Given the complexity of the effects of alcohol consumption on personal health, women could usefully discuss these risks and benefits with their physician.

\section{Strengths and limitations}

Strengths of our study include the large sample size, the prospective design with 24 years of follow-up and high response rates, and the repeated collection of detailed information on lifestyle. Some measurement error is inevitable, particularly in the assessment of diet and physical activity, and is likely to have weakened the associations seen. We would probably have seen a lower mortality if we had used more restrictive criteria for the low risk group (for example, healthy diet score in the highest fifth). However, our results indicate that even modest differences in lifestyle can have a substantial impact on reducing mortality. Although residual confounding can never be excluded in nonrandomised studies, evidence from prospective studies in other populations and randomised controlled trials supports our findings. Because incomplete adjustment for smoking habits can weaken the association between overweight and mortality, ${ }^{11}$ our estimates for the association between overweight and mortality in never smokers may be more accurate than those for the total study population. Variation in socioeconomic status in our study of registered nurses was more limited than in the general population. Consistent with results from a British study, ${ }^{33}$ adjustment for various measures of socioeconomic status did not appreciably affect associations between lifestyle factors and mortality during follow-up. In analyses with mortality as an end point, confounding by poor health that precedes

\begin{tabular}{|c|c|c|c|}
\hline & Death from any cause & Cardiovascular death & Cancer death \\
\hline \multicolumn{4}{|c|}{ Three risk factors: low diet quality, low physical activity, overweight $†$} \\
\hline \multicolumn{4}{|l|}{ Relative risk $(95 \% \mathrm{Cl})$ : } \\
\hline No risk factors $(7.7 \%) \ddagger$ & 1.00 & 1.00 & 1.00 \\
\hline One risk factor (27\%) & 1.20 (1.02 to 1.43$)$ & 1.44 (0.91 to 2.27$)$ & 1.19 (0.95 to 1.49$)$ \\
\hline Two risk factors (41\%) & 1.54 (1.31 to 1.81$)$ & 2.24 (1.44 to 3.46$)$ & 1.37 (1.11 to 1.70$)$ \\
\hline Three risk factors (25\%) & 2.17 (1.83 to 2.57$)$ & $3.58(2.30$ to 5.58$)$ & 1.75 (1.39 to 2.19$)$ \\
\hline $\begin{array}{l}\text { Population attributable risk (\%) for } \\
\text { having any of the three risk factors }(95 \% \\
\text { Cl) }\end{array}$ & $34.3(18.9$ to 48.0$)$ & $56.1(27.7$ to 75.5$)$ & $22.8(-0.01$ to 44.3$)$ \\
\hline \multicolumn{4}{|c|}{ Four risk factors: above three and alcohol abstinence or heavy drinking§ } \\
\hline \multicolumn{4}{|l|}{ Relative risk $(95 \% \mathrm{Cl})$} \\
\hline No risk factors $(5.4 \%) \ddagger$ & 1.00 & 1.00 & 1.00 \\
\hline One risk factor (20\%) & $1.25(1.01$ to 1.53$)$ & $1.18(0.70$ to 1.99$)$ & 1.39 (1.05 to 1.83$)$ \\
\hline Two risk factors (34\%) & $1.48(1.22$ to 1.81$)$ & 1.78 (1.08 to 2.92$)$ & 1.42 (1.08 to 1.85$)$ \\
\hline Three risk factors (30\%) & 1.95 (1.60 to 2.38$)$ & 2.64 (1.61 to 4.33$)$ & $1.70(1.30$ to 2.22$)$ \\
\hline Four risk factors (10\%) & 2.64 (2.13 to 3.26$)$ & 3.94 (2.35 to 6.60$)$ & 2.11 (1.57 to 2.83$)$ \\
\hline $\begin{array}{l}\text { Population attributable risk (\%) for } \\
\text { having any of the four risk factors ( } 95 \% \\
\text { Cl) }\end{array}$ & 41.5 (24.3 to 56.2$)$ & 60.9 (28.3 to 80.9) & $25.7(-1.4$ to 49.3$)$ \\
\hline \multicolumn{4}{|c|}{$\begin{array}{l}\text { * Relative risks and population attributable risks adjusted for age ( } 5 \text { year age categories) and time period (four periods); additionally adjusted fo } \\
\text { alcohol consumption }(0,1-4,5-14,15-29, \geq 30.0 \mathrm{~g} / \mathrm{d}) \text { for the "three risk factor" model. } \\
\text { †Low diet quality: healthy diet score in lower three fifths; low physical activity: « } 30 \mathrm{~min} / \text { day; overweight: body mass index } \geq 25 \text {. } \\
\text { †Prevalence in } 1990 \text {. } \\
\S 0 \text { or } \geq 15 \mathrm{~g} / \text { day alcohol. }\end{array}$} \\
\hline
\end{tabular}




\section{WHAT IS ALREADY KNOWN ON THIS TOPIC}

Many studies have shown that individual lifestyle factors are associated with risk of chronic diseases

Few studies have evaluated the effects of combinations of lifestyle factors on mortality

\section{WHAT THIS STUDY ADDS}

Most deaths during 24 years of follow-up in middle aged women could have been avoided by a combination of not smoking, maintaining a healthy weight, regular physical activity, and a healthy diet

These findings underscore the importance of intensifying both efforts to eradicate cigarette smoking and those aimed at improving diet and physical activity

death and affects lifestyle habits (for example, resulting in weight loss, reduced alcohol consumption, and physical inactivity) is of particular concern. For this reason, we excluded women with conditions that may reflect this poor health status at baseline. Also, our findings were consistent with results in analyses of lifestyle factors and risk of incidence of chronic diseases that are less likely to be affected by this type of confounding. ${ }^{153740}$

Because population attributable risks depend on both relative risks and the prevalence of risk factors (the higher the prevalence, the higher the population attributable risk) the prevalence of risk factors has to be considered when generalising our findings to other populations. For example, compared with the prevalence of $48 \%$ in our cohort, overweight (body mass index $\geq 25$ ) was more common in women in national surveys in the United States (62\%) and England (59\%), similar in Greece $(46 \%)$ and Spain $(48 \%)$, and less common in Italy $(35 \%)$ and the Netherlands $(39 \%){ }^{4142}$ As a result, population attributable risks for individual risk factors will differ somewhat by population, but we believe that our overall conclusions are generally applicable to middle aged women in high income countries. However, our participants were predominantly white and confirmation in other ethnic groups is warranted.

\section{Conclusions}

Avoiding cigarette smoking is of pivotal importance for the prevention of premature death. In our study of middle aged women, adherence to lifestyle guidelines involving a healthy diet, regular physical activity, and weight management was also associated with markedly lower mortality. Of note, our results indicate that a healthy diet and regular physical activity have important health benefits independent of reducing adiposity. These findings underscore the importance of intensifying both efforts to eradicate cigarette smoking and those aimed at improving diet and physical activity.

We thank the participants of the nurses' health study for their continued participation, Ellen Hertzmark for expert programming help, and Walter Willett and Meir Stampfer for their valuable comments on the manuscript. The article adheres to the STROBE guidelines (www.strobe-statement. org/).

Contributors: RMvD and FBH had the idea for the study. TL did the data analysis. RMvD, TL, DS, and FBH provided statistical expertise. RMvD wrote the first draft of the paper. FBH obtained funding. All authors contributed to the interpretation of the results and critical revision of the manuscript for important intellectual content and approved the final version of the manuscript. RMvD is the guarantor.

Funding: This research was supported by National Institutes of Health (NIH) grants CA87969 and HL60712. RMvD was partly supported by an unrestricted research grant from the Peanut Foundation. The funding sources had no role in the collection, management, analysis, or interpretation of the data and had no role in the preparation, review, or approval of the manuscript. The content is solely the responsibility of the authors and does not necessarily represent the official views of the NIH. Competing interests: None declared.

Ethical approval: The institutional review board at Brigham and Women's Hospital approved this study.

Provenance and peer review: Not commissioned; externally peer reviewed.

1 Hu FB, Manson JE, Stampfer MJ, Colditz G, Liu S, Solomon CG, et al. Diet, lifestyle, and the risk of type 2 diabetes mellitus in women. $N$ Engl J Med 2001;345:790-7.

2 Tuomilehto J, Lindström J, Eriksson JG, Valle $\Pi$, Hämäläinen $\mathrm{H}$, Ilanne-Parikka $P$, et al. Prevention of type 2 diabetes mellitus by changes in lifestyle among subjects with impaired glucose tolerance. N Engl J Med 2001;344:1343-50.

3 De Lorgeril M, Renaud S, Mamelle N, Salen P, Martin JL, Monjaud I, et al. Mediterranean alpha-linolenic acid-rich diet in secondary prevention of coronary heart disease. Lancet 1994;343:1454-9.

4 Sacks FM, Katan M. Randomized clinical trials on the effects of dietary fat and carbohydrate on plasma lipoproteins and cardiovascular disease. Am J Med 2002;113(suppl 9B):13-24S.

5 Stampfer MJ, Hu FB, Manson JE, Rimm EB, Willett WC. Primary prevention of coronary heart disease in women through diet and lifestyle. N Engl J Med 2000;343:16-22.

6 Key TJ, Schatzkin A, Willett WC, Allen NE, Spencer EA, Travis RC. Diet, nutrition and the prevention of cancer. Public Health Nutr 2004;7:187-200.

7 Vineis P, Alavanja M, Buffler P, Fontham E, Franceschi S, Gao YT, et al. Tobacco and cancer: recent epidemiological evidence. J Natl Cancer Inst 2004;96:99-106.

8 Mokdad AH, Marks JS, Stroup DF, Gerberding JL. Actual causes of death in the United States, 2000. IAMA 2004:291:1238-45. [Correction in JAMA 2005;293:293-4.]

9 Ezzati M, Vander Hoorn S, Lopez AD, Danaei G, Rodgers A, Mathers $C D$, et al. Comparative quantification of mortality and burden of disease attributable to selected risk factors. In: Lopez AD, Mathers CD, Ezzati M, Jamison DT, Murray CJL, eds. Global burden of disease and risk factors. New York: Oxford University Press, 2006:241-68.

10 Knoops KT, de Groot LC, Kromhout D, Perrin AE, Moreiras-Varela O, Menotti A, et al. Mediterranean diet, lifestyle factors, and 10-year mortality in elderly European men and women: the HALE project.JAMA 2004;292:1433-9.

11 Manson JE, Stampfer MJ, Hennekens CH, Willett WC. Body weight and longevity: a reassessment. JAMA 1987;257:353-8.

12 Willett WC. Nutritional epidemiology: monographs in epidemiology and biostatistics.Vol 30. New York: Oxford University Press, 1998.

13 Salvini S, Hunter DJ, Sampson L, Stampfer MJ, Colditz GA, Rosner B, et al. Food-based validation of a dietary questionnaire: the effects of week-to-week variation in food consumption. Int / Epidemiol 1989;18:858-67.

14 Giovannucci E, Colditz G, Stampfer MJ, Rimm EB, Litin L, Sampson L, et al. The assessment of alcohol consumption by a simple selfadministered questionnaire. Am J Epidemiol 1991;133:810-7.

15 Wolf AM, Hunter DJ, Colditz GA, Manson JE, Stampfer MJ, Corsano KA, et al. Reproducibility and validity of a self-administered physical activity questionnaire. Int J Epidemiol 1994;23:991-9.

16 Rimm EB, Stampfer MJ, Colditz GA, Chute CG, Litin LB, Willett WC Validity of self-reported waist and hip circumferences in men and women. Epidemiology 1990;1:466-73.

17 WHO. Obesity: preventing and managing the global epidemic. Report of a WHO consultation on obesity. Geneva: WHO, 1997.

18 Pate RR, Pratt M, Blair SN, Haskell WL, Macera CA, Bouchard C, et al. Physical activity and public health: a recommendation from the Centers for Disease Control and Prevention and the American College of Sports Medicine. JAMA 1995;273:402-7.

19 McCullough ML, Feskanich D, Stampfer MJ, Giovannucci EL, Rimm EB, $\mathrm{Hu} \mathrm{FB}$, et al. Diet quality and major chronic disease risk in men and women: moving toward improved dietary guidance. Am J Clin Nutr 2002;76:1261-71.

20 Rich-Edwards JW, Corsano KA, Stampfer MJ. Test of the National Death Index and Equifax nationwide death search. Am J Epidemiol 1994;140:1016-9. 
21 Spiegelman D, Hertzmark E, Wand HC. Point and interval estimates of partial population attributable risks in cohort studies: examples and software. Cancer Causes Control 2007;18:571-9.

22 D’Agostino RB, Lee ML, Belanger AJ, Cupples LA, Anderson K, Kannel WB. Relation of pooled logistic regression to time dependent Cox regression analysis: the Framingham heart study. Stat Med 1990;9:1501-15.

23 Wacholder S, Benichou J, Heineman EF, Hartge P, Hoover RN. Attributable risk: advantages of a broad definition of exposure. Am Epidemiol 1994;140:303-9.

24 Greenland S, Drescher K. Maximum likelihood estimation of the attributable fraction from logistic models. Biometrics 1993;49:865-72.

25 Graubard BI, Fears TR. Standard errors for attributable risk for simple and complex sample designs. Biometrics 2005;61:847-55.

26 Hu FB, Stampfer MJ, Rimm E, Ascherio A, Rosner BA, Spiegelman D, et al. Dietary fat and coronary heart disease: a comparison of approaches for adjusting for total energy intake and modeling repeated dietary measurements. Am J Epidemiol 1999;149:531-40.

27 Khaw KT, Wareham N, Bingham S, Welch A, Luben R, Day N. Combined impact of health behaviours and mortality in men and women: the EPIC-Norfolk prospective population study. PLoS Med 2008; 5:e12.

28 Anthonisen NR, Skeans MA, Wise RA, Manfreda J, Kanner RE, Connett JE. The effects of a smoking cessation intervention on 14.5year mortality: a randomized clinical trial. Ann Intern Med 2005;142:233-9.

29 Rimm EB, Williams P, Fosher K, Criqui M, Stampfer MJ. Moderate alcohol intake and lower risk of coronary heart disease: meta-analysis of effects on lipids and haemostatic factors. BMJ 1999;319:1523-8.

30 Mensink RP, Zock PL, Kester AD, Katan MB. Effects of dietary fatty acids and carbohydrates on the ratio of serum total to HDL cholestero and on serum lipids and apolipoproteins: a meta-analysis of 60 controlled trials. Am J Clin Nutr 2003;77:1146-55.

31 Appel LJ, Moore TJ, Obarzanek E, Vollmer WM, Svetkey LP, Sacks FM, et al. A clinical trial of the effects of dietary patterns on blood pressure. N Engl J Med 1997;336:1117-24.
32 Pereira MA, Jacobs DR Jr, Pins JJ, Raatz SK, Gross MD, Slavin JL, et al. Effect of whole grains on insulin sensitivity in overweight hyperinsulinemic adults. Am J Clin Nutr 2002;75:848-55.

33 Wannamethee SG, Shaper AG, Walker M, Ebrahim S. Lifestyle and 15year survival free of heart attack, stroke, and diabetes in middle-aged British men. Arch Intern Med 1998;158:2433-40.

34 Corrao G, Bagnardi V, Zambon A, La Vecchia C. A meta-analysis of alcohol consumption and the risk of 15 diseases. Prev Med 2004;38:613-9.

35 Rehm J, Gmel G, Sempos CT, Trevisan M. Alcohol-related morbidity and mortality. Alcohol Res Health 2003;27:39-51.

36 Di Castelnuovo A, Costanzo S, Bagnardi V, Donati MB, lacoviello L, de Gaetano G. Alcohol dosing and total mortality in men and women: an updated meta-analysis of 34 prospective studies. Arch Intern Med 2006;166:2437-45.

37 Smith-Warner SA, Spiegelman D, Yaun SS, van den Brandt PA, Folsom AR, Goldbohm RA, et al. Alcohol and breast cancer in women: a pooled analysis of cohort studies. JAMA 1998;279:535-40.

38 Colhoun H, Ben-Shlomo Y, Dong W, Bost L, Marmot M. Ecological analysis of collectivity of alcohol consumption in England: importance of average drinker. BMJ 1997;314:1164-8.

39 Fuchs CS, Stampfer MJ, Colditz GA, Giovannucci EL, Manson JE, Kawachi I, et al. Alcohol consumption and mortality among women. $N$ Engl J Med 1995;332:1245-50.

40 Martinez ME, Giovannucci E, Spiegelman D, Hunter DJ, Willett WC Colditz GA. Leisure-time physical activity, body size, and colon cance in women. J Natl Cancer Inst 1997;89:948-55.

41 Ogden CL, Carroll MD, Curtin LR, McDowell MA, Tabak CJ, Flegal KM Prevalence of overweight and obesity in the United States, 19992004. JAMA 2006;295:1549-55.

42 Van der Wilk EA. Prevalence of overweight (BMI 25-29.9) and obesity (BMI 30+) in European countries. 2008. www.euphix.org/ object_document/04620n27195.html.

Accepted: 22 July 2008 